\title{
The Influence of Hydrophobic Solvation on the Alkaline Hydrolysis of Ethyl Esters of Polar Sub- stituted 2-Methylpropionic Acids in Water ${ }^{1}$
}

\author{
G. Schmeer, ${ }^{2}$ S. Riembauer, ${ }^{2}$ and J. Barthel ${ }^{2}$ \\ Received October 18, 1989; in Final Form August 2, 1990
}

\begin{abstract}
The rate constants of the alkaline hydrolysis of 2-methylpropionic acid ethyl ester, $\alpha$-hydroxy, $\alpha$-bromo, $\alpha$-cyano, and $\alpha$-nitro-2-methylpropionic acid ethyl ester have been measured in water between $5^{\circ} \mathrm{C}$ and $45^{\circ} \mathrm{C}$ with the help of an appropriate conductance bridge developed in our laboratory. The influence of the polar substituents on the rate constant, $a$ powerful probe for discussing two-particle interactions in solutions, is characterized by an intramolecular structure parameter of the activated complex and a dielectric parameter of its surroundings. The dependence of the reaction rate on the structure parameter is compared to that of substituted acetic acid derivatives. The smaller dielectric parameter of 2 methylpropionic acid esters reveals the increasing hydrophobic solvation in comparison to acetic acid derivatives.
\end{abstract}

KEY WORDS: 2-Methylpropionic acid esters; alkaline hydrolysis; polar substituent effect; hydrophobic solvation; chemical model.

\section{Introduction}

A chemical reaction

$$
\mathrm{A}+\mathrm{B} \rightleftarrows X^{\ddagger} \rightarrow \text { Products }
$$

between the reactants $A$ and $B$ procedes by the formation of the activated complex $X^{\ddagger}$ which, in turn, decomposes into the final products; $A$ and $B$ are ions or molecules of arbitrary internal charge distribution. The chemical model, (1) a Hamiltonian model at the Mayer-McMillan level, permits the statistical thermodynamic calculation of the Gibbs'

\footnotetext{
${ }^{1}$ The $7^{\text {th }}$ communication of investigations on substituent and solvent effects of solvolysis reactions.

${ }^{2}$ Institut für Physikalische und Theoretische Chemie, der Universität Regensburg, D-8400 Regensburg, West Germany.
} 
energy of activation $\Delta G^{\ddagger}$ via the interaction potential of paired states of particles $A$ and $B$ of any type of internal charge distribution in solution. Therefore, the study of activated complex formation is a powerful probe to corroborate model calculations on two-particle interactions in solutions.

In preceding papers, chemical model calculations were used to probe ion-ion, ion-dipole, ion-induced dipole, dipole-dipole, dipoleinduced dipole, and induced dipole-induced dipole interaction potentials with the help of kinetic salt, permittivity, and substituent effects resulting from a series of measurements in which the variation of ionic force, solvent permittivity, or polar groups of the reactants yielded information on the chemical model parameters. ${ }^{(2-9)}$ The key functions of such investigations are the Gibbs' energy $\Delta G^{\ddagger}$, enthalpy $\Delta G^{\ddagger}$, and entropy $\Delta S^{\ddagger}$ of activation which are related to the reaction rate $k$ of reaction (1) by

$$
k=\frac{R_{\mathrm{g}} T}{N_{\mathrm{A}} h} \exp \left[\frac{-\Delta G^{\ddagger}}{R_{\mathrm{g}} T}\right]=\frac{R_{\mathrm{g}} T}{N_{\mathrm{A}} h} \exp \left[-\frac{1}{R_{\mathrm{g}}}\left(\frac{\Delta H^{\ddagger}}{T}-\Delta S^{\ddagger}\right)\right]
$$

where $R_{\mathrm{g}}\left(R_{\mathrm{g}}=N_{\mathrm{A}} k_{\mathrm{B}}\right)$ is the gas constant, $k_{\mathrm{B}}$ is the Boltzmann constant, $N_{\mathrm{A}}$ is Avogadro's number, $h$ is Planck's constant, and $T$ is the Kelvin temperature.

\subsection{Alkaline Ester Hydrolysis}

The alkaline hydrolysis of esters, acid fluorides, $n$-acyl pyrazoles and $n$-acyl imidazoles has been extensively studied in our laboratory to obtain information on the effects of ionic strength, solvent permittivity of mixed solvent systems, ion-pair catalysis, and polar substituents of the polar molecule. According to Ingold a $B_{\mathrm{Ac}} 2$ mechanism is proposed.

$$
\mathrm{OH}^{-}+\mathrm{G}-\stackrel{\mathrm{O}}{\mathrm{C}}-\mathrm{Y} \rightleftharpoons[\mathrm{G}-\underset{\underset{\mathrm{OH}}{\mathrm{C}}-\mathrm{Y}}{\mathrm{O}}] \rightarrow \mathrm{G}-\mathrm{CO}_{2}^{-}+\mathrm{YH}
$$

Here, $G=\mathrm{CH}_{3}, \mathrm{CH}_{2} \mathrm{~F}, \mathrm{CHF}_{2}, \mathrm{CF}_{3}, \mathrm{CH}_{2} \mathrm{Cl}, \mathrm{CHCl}_{2}, \mathrm{CCl}_{3} \mathrm{CH}_{2} \mathrm{Br} \mathrm{CH}_{2} \mathrm{I}$ $\mathrm{CH}_{2} \mathrm{OH} \mathrm{CH} \mathrm{CCH}_{3}$ and $Y=\mathrm{OCH}_{3} \mathrm{OC}_{2} \mathrm{H}_{5}$, F, pyrazole, imidazole. In the first reaction step the base $\mathrm{OH}^{-}$is reversibly added at the carboxyl carbon atom of the acid derivative forming a tetrahedral activated com- 
plex $X^{\ddagger}$ which in alkaline solutions irreversibly decomposes to $\mathrm{YH}$ and the carboxylic acid anion G- $\mathrm{CO}_{2}^{-}$. The formation of $Y H$ or $\mathrm{Y}^{-}$in alkaline solution depends on the acidity constant of the acid $Y H$. As an example, the activated complex of the alkaline hydrolysis of ethyl chloroacetate is given in Fig. 1.

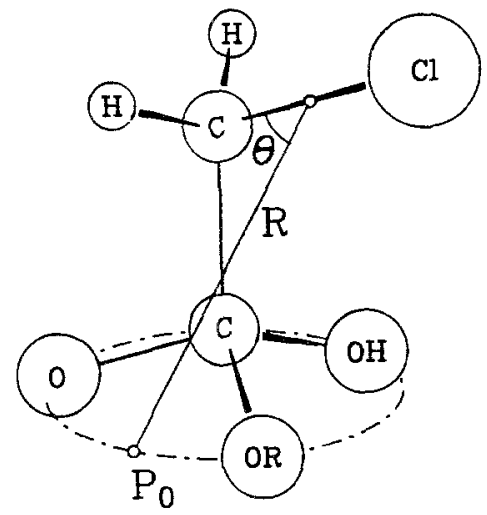

Fig. 1. Structure of the activated complex of the alkaline hydrolysis of esters, exemplified for ethyl chloroacetate $\left(P_{0}\right.$ is the position of the negative charge $e z_{\mathrm{A}}$ in the activated complex with respect to the origin of the coordinate system placed in the $\mathrm{C}-\mathrm{Cl}$ bond.)

The activated complex shows tetrahedral symmetry of the two $\mathrm{C}$ $\mathrm{O}$ and the $\mathrm{C}-\mathrm{Y}$-bonds at the carboxyl group, in contrast to the initial product $\mathrm{G}-\mathrm{C}(\mathrm{O}) \mathrm{Y}$ which is planar at this carbon atom; the negative charge is located on the circle through the two oxygen atoms and the hetero-atom of the group $Y$. The remaining part of the molecule $X^{\text {t }}$ shows free rotation around the C-C bond to the $\alpha$-carbon atom. The internal charge distribution of $X^{\ddagger}$ is given by the electronegativities of the atoms, the lengths and angles of the bonds connecting the atoms of the molecule. The different electronegativities of oxygen and nitrogen or fluorine of the carboxyl group must not be taken into account for a discussion of hindered rotation. (5) The bond lengths and bond angles are taken from standard reference tables. ${ }^{(10)}$

The Gibbs' energy of activation is the molar energy of formation of the activated complex $X^{\ddagger}$ from the initially infinitely distant compounds $\mathrm{A}$ and $\mathrm{B}$. It is related to the two-particle interaction potential of the mean force, $W_{\mathrm{AB}}^{ \pm}(R, \Theta, \Phi)$, by the equation

$$
\Delta G^{\ddagger}=N_{\mathrm{A}} W_{\mathrm{A} \mathrm{B}}^{\ddagger}(R, \Theta, \Phi)
$$

It is important to note that $R, \Theta, \Phi$ are the coordinates of the reacting particles in the coordinate system of the activated complex $X^{\dot{\ddagger}}$, 
which may have an internal charge distribution different from that resulting from the addition of the particle structures of $A$ and $B, c . f$. Ref. 2.

In appropriately chosen measurement series, only the parameters controlling the investigated effect are changed and the contributions of the other effects are held constant when compared to a standard reaction (subscript zero)

$$
\ln k-\ln k_{\mathrm{o}}=\frac{1}{R_{\mathrm{g}} T}\left[\Delta G_{\mathrm{o}}^{\ddagger}-\Delta G^{\ddagger}\right]
$$

The energy of activation may be split into its electrostatic $\left(\Delta G^{\mathrm{el}}\right)$ and non-electrostatic $\left(\Delta G^{*}\right)$ parts

$$
\Delta G^{\ddagger}=\Delta G^{\mathrm{el}}+\Delta G^{*}
$$

The non-electrostatic part of $\Delta G^{*}$ is due to solvation, H-bonding and other "chemical" forces and may be neglected in series where

$$
\left|\Delta G_{\mathrm{o}}^{*}-\Delta G^{*}\right|<<\left|\Delta G_{\mathrm{o}}^{\mathrm{el}}-\Delta G^{\mathrm{el}}\right|
$$

produced by the maintenance of an unchanged vicinity of the reaction center for all reactions.

The electrostatic Gibbs' energy of activation, $\Delta G^{\mathrm{el}}$, is

$$
\Delta G^{\mathrm{el}}=N_{\mathrm{A}} e z_{\mathrm{A}} \Psi_{\mathrm{B}}(R, \Theta, \Phi)
$$

if the charge $e z_{\mathrm{A}}$ ( $e$, charge of the proton; $z_{\mathrm{A}}$, ion valence) of the ion $\mathrm{A}$ is transferred from infinite distance to the point $P(R, \Theta, \Phi)$ in the activated complex $X^{\ddagger}$ where the electric potential produced by molecule $B$ is $\Psi_{\mathrm{B}}(R, \Theta, \Phi)$.

For the calculation of the potential $\Psi_{\mathrm{B}}$ the assumption is made that the activated complex $X^{*}$ is a spherical particle of radius $R_{1}$ with inner permittivity $\varepsilon_{\mathrm{i}}$ imbedded in a solvent of permittivity $\varepsilon$. $\Psi_{\mathrm{B}}$ is found to be the product of a function $f\left(\varepsilon, R_{1}\right)$ and the intramolecular structure parameter $\Delta\left(\mu \cos \Theta / R^{2}\right){ }^{(2)} \mu$ is the dipole moment of the polar substituent. It is taken as dipole moment in the gas phase from the literature. ${ }^{(11)}$ The function $f\left(\varepsilon, R_{1}\right)$ depends on the electrostatic properties of the solvent and the dielectric sphere. Equation (5) is then transformed to

$$
\ln k-\ln k_{\mathrm{o}}=\frac{1}{R_{\mathrm{g}} T} N_{\mathrm{A}} e z_{\mathrm{A}} f\left(\varepsilon, R_{1}\right) \Delta\left(\mu \frac{\cos \Theta}{R^{2}}\right)
$$

All plots of $\left(\ln k-\ln k_{\mathrm{o}}\right) v s . \Delta\left(\mu \cos \Theta / R^{2}\right)$ for reactions of GCOY 


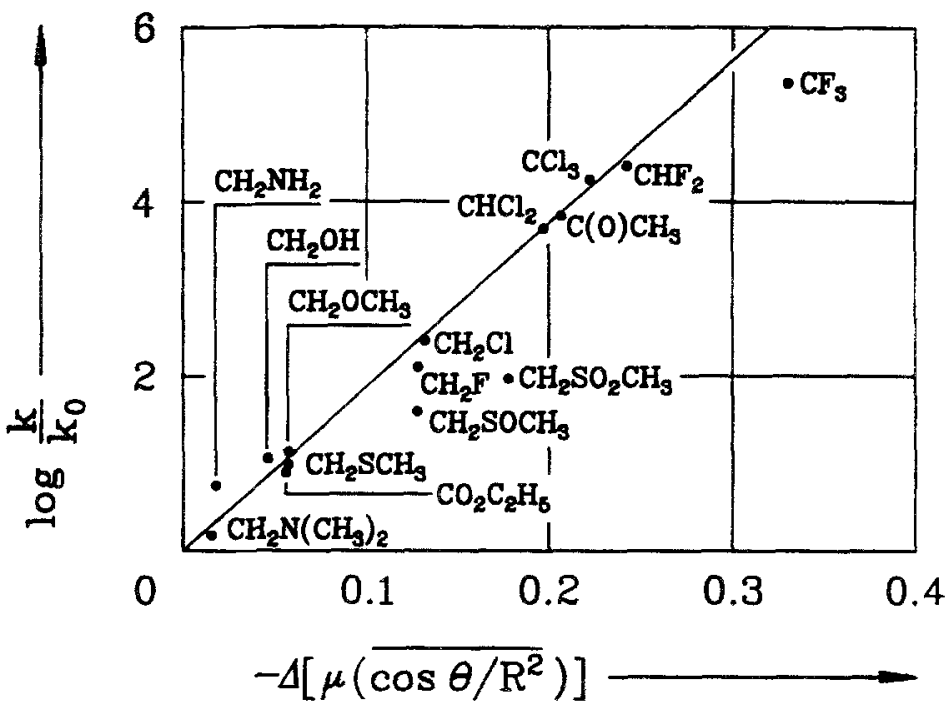

Fig. 2. Polar substituent effect, $\log \left(k / k_{0}\right)$ vs. $f\left(\Delta\left[\mu\left(\cos \theta / R^{2}\right]\right)\right.$, on the alkaline hydrolysis of substituted ethyl acetates in water at $25^{\circ} \mathrm{C}$.

with $\mathrm{OH}^{-}$, where $\mathrm{G}=\mathrm{CH}_{3}, \mathrm{CH}_{2} \mathrm{~F}, \mathrm{CHF}_{2}, \mathrm{CF}_{3}, \mathrm{CH}_{2} \mathrm{Cl}, \mathrm{CHCl}_{2}, \mathrm{CCl}_{3}$, $\mathrm{CH}_{2} \mathrm{Br}, \mathrm{CH}_{2} \mathrm{I}, \mathrm{CH}_{2} \mathrm{OH}, \mathrm{CH}_{2} \mathrm{OCH}_{3}$, yield a common linear function, independent of $Y$, with $Y=\mathrm{OCH}_{3} \mathrm{OC}_{2} \mathrm{H}_{5}, F, \mathrm{OC}_{6} \mathrm{H}_{4} \mathrm{NO}_{2}, \mathrm{~N}_{2} \mathrm{C}_{3} \mathrm{H}_{3}$ (pyrazole or imidazole). Examples are given in Fig. 2.

The influence of the solvent via the function $f\left(\varepsilon, R_{1}\right)$ is almost independent of the permittivity $\varepsilon$ in the range $40 \leq \varepsilon \leq 78$ as shown by measurements of the alkaline hydrolysis of acetic acid esters in waterdioxane mixtures. ${ }^{(5)}$

\subsection{Hydration of the Activated Complex}

Replacement of the substituents $\mathrm{XH}_{2} \mathrm{C}$ of the preceding investigations by the bulky and hydrophobic substituents $\mathrm{X}\left(\mathrm{CH}_{3}\right)_{2} \mathrm{C}, \mathrm{X}=\mathrm{H}, \mathrm{OH}$, $\mathrm{Br}, \mathrm{CN}$ and $\mathrm{NO}_{2}$ producing the respective esters of $\alpha$ substituted 2methylpropionic acids $\mathrm{XC}\left(\mathrm{CH}_{3}\right)_{2}-\mathrm{CO}_{2} \mathrm{C}_{2} \mathrm{H}_{5}$, also yields a straight line $\left(\ln k-\ln k_{\mathrm{o}}\right) v s . \Delta\left(\mu \cos \Theta / R^{2}\right)$. However, the slope of this straight line differs significantly from that of Fig. 2.

As to $R$ and $\Theta$ the substitution of two hydrogen atoms by two methyl groups does not change the geometry of the activated complex, the electrostatic contributions of a hydrogen atom and a methyl group also are equal and hence the intramolecular structure parameter $\Delta\left(\mu \cos \Theta / R^{2}\right)$ is the same for polar substituted acetic acid and 2methylpropionic acid derivatives, respectively. 


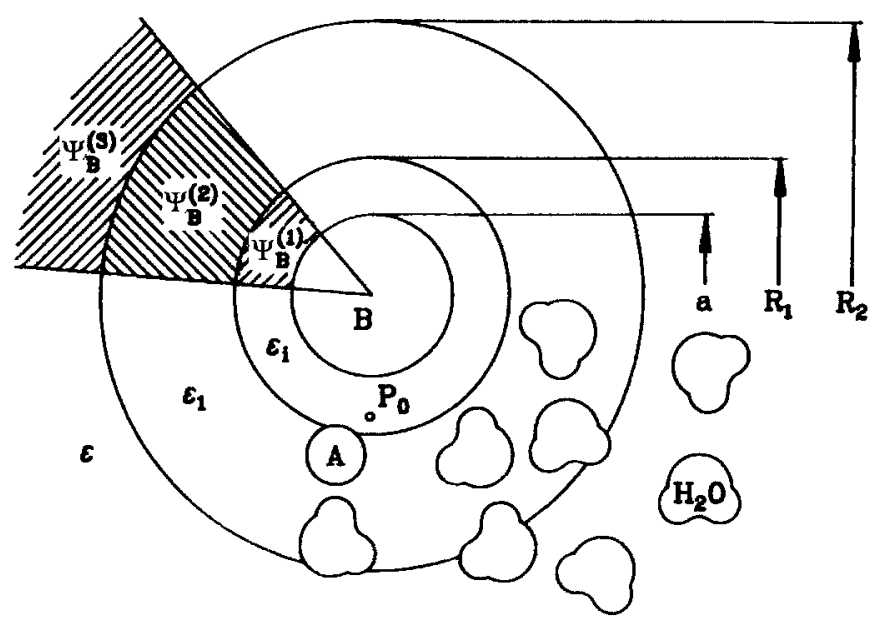

Fig. 3. The chemical model of the activated complex of the alkaline solvolysis reactions. (For explanation of the symbols see the text).

Since the mechanism of the alkaline hydrolysis of 2methylpropionic acid esters is also of the type $B_{\mathrm{Ac}} 2$, the shift of the rate constant $\ln \left(k / k_{0}\right)$ should obey the same rules as the acetic acid esters. The difference in the slopes shows the influence of the solvent on the reactions. This solvent effect is studied in the following part of the paper.

The different behavior of acetic acid and 2-methylpropionic acid esters can be taken into account by a more refined chemical model ${ }^{(1)}$ of the activated complex and its surroundings, by subdividing the space around the activated complex into three regions (see Fig. 3): (i) $a \leq r<R_{1}$, defining the charge free shell of the dielectric sphere of permittivity $\varepsilon_{\mathrm{i}}$ with radius $R_{1}$. All charges of the neutral molecule $B$ are located within the sphere of radius $a$. The position $P_{0}$ (see Fig. 2) of the hydroxide ion $A$ in the activated complex is in this region; (ii) $R_{1} \leq r<R_{2}$, characterizing the inner solvation shell of the activated complex with the permittivity $\varepsilon_{1}$; and (iii) $R_{2} \leq r$, the region of the bulk solution of permittivity $\varepsilon$ and the ionic strength characterized by the Debye parameter $\kappa$.

The electrostatic potential produced by an arbitrary charge distribution in its surroundings at arbitrary coordinates $r, \Theta$, and $\phi$ is given by the Poisson-Boltzmann equations 


$$
\begin{aligned}
& \Delta \Psi_{\mathrm{B}}^{(1)}(r, \theta, \phi)=0 ; a \leq r<R_{1} ; \varepsilon=\varepsilon_{\mathrm{i}} \\
& \Delta \Psi_{\mathrm{B}}^{(2)}(r, \theta, \phi)=0 ; R_{1} \leq r<R_{2} ; \varepsilon=\varepsilon_{1} \\
& \Delta \Psi_{\mathrm{B}}^{(3)}(r, \theta, \phi)=\kappa^{2} \Psi_{\mathrm{B}}^{(3)}(r, \theta, \phi) ; R_{2} \leq r<\infty ; \varepsilon=\varepsilon
\end{aligned}
$$

The solution of Eqs. (10) is performed with the help of the boundary conditions

$$
\begin{array}{r}
\lim _{R_{1} \rightarrow \infty} \Psi_{\mathrm{B}}^{(1)}(r, \theta, \phi)=\Psi_{\mathrm{B}}^{(0)}(r, \theta, \phi) ; \lim _{r \rightarrow \infty} \Psi_{\mathrm{B}}^{(3)}(r, \theta, \phi)=0 \\
\Psi_{\mathrm{B}}^{(1)}\left(R_{1}, \theta, \phi\right)=\Psi_{\mathrm{B}}^{(2)}\left(R_{1}, \theta, \phi\right) ; \Psi_{\mathrm{B}}^{(2)}\left(R_{2}, \theta, \phi\right)=\Psi_{\mathrm{B}}^{(3)}\left(R_{2}, \theta, \phi\right) \\
\varepsilon_{\mathrm{i}}\left(\frac{\partial \Psi_{\mathrm{B}}^{(1)}}{\partial r}\right)_{\mathrm{r}=\mathrm{R}_{1}}=\varepsilon_{1}\left(\frac{\partial \Psi_{\mathrm{B}}^{(2)}}{\partial r}\right)_{\mathrm{r}=\mathrm{R}_{1}} ; \varepsilon_{1}\left(\frac{\partial \Psi_{\mathrm{B}}^{(2)}}{\partial r}\right)_{\mathrm{r}=\mathrm{R}_{2}}=\varepsilon\left(\frac{\partial \Psi_{\mathrm{B}}^{(3)}}{\partial r}\right)_{\mathrm{r}=\mathrm{R}_{2}}
\end{array}
$$

The first boundary condition yields the unperturbed potential $\Psi_{B}^{(0)}(r, \theta, \phi)$ of the isolated charge distribution in an infinitely large sphere of permittivity $\varepsilon_{\mathrm{i}}$. The second boundary condition shows the attenuation to zero of the electric potential at infinite distance. The four other boundary conditions reflect the continuous transitions of the electric field $\vec{E}$ and the dielectric displacement $\vec{D}$ at the interfaces of the dielectric spheres. The potential $\Psi_{B}^{(0)}(r, \theta, \phi)$ is given by

$$
\Psi_{\mathrm{B}}^{(0)}(r, \theta, \phi)=\sum_{j=0}^{\infty} \sum_{m=-j}^{j} \frac{b_{j}^{(\mathrm{m})}}{4 \pi \varepsilon_{0} \varepsilon_{\mathrm{i}}} \frac{1}{r^{j+1}} P_{\mathrm{J}}^{(\mathrm{m})}(\cos \theta) e^{\mathrm{im} \phi}
$$

with the help of the associated Legendre Polynomials $P_{\mathrm{J}}^{(\mathrm{m})}(\cos \theta)$ and the coefficients $b_{\mathrm{J}}^{(\mathrm{m})}$ of the isolated charge distribution.

The potential $\Psi_{\mathrm{B}}(r, \theta, \phi)$ of $B$ in the solution may be subdivided into the contribution $\psi_{\mathrm{B}}(r, \theta, \phi)$ produced by the polar substituent and that of the rest of the acivated complex $\psi^{\text {res }}(r, \theta, \phi)$. The substituent parameters calculated by means of bond lengths and angles from tables of interatomic distances ${ }^{(\mathbf{i 0})}$ and dipole moments in the gas phase ${ }^{(11)}$ are collected in Table IV. In the case of nonlinear and multiatomic substituents the dipole moment is averaged as the effective moment in the direction of the $\mathrm{C}$-X-bond under the assumption of free rotation of all single bonds.

The reaction rate determining part of the electrostatic potential is that of the region $a \leq r<R_{1}$. It is obtained as the solution of the set of Eqs. (10-12) at low ionic strength at the point $P(R, \Theta, \Phi)$ 


$$
\begin{gathered}
\Psi_{\mathrm{B}}(R, \Theta, \Phi)=\psi_{\mathrm{B}}(R, \Theta, \Phi)+\psi^{\mathrm{res}}(R, \Theta, \Phi) \\
=\frac{1}{4 \pi \varepsilon_{\mathrm{o}} \varepsilon_{\mathrm{i}}}\left[1-\frac{2(1-\eta)\left(\varepsilon+\varepsilon_{1}\right)-(2 \eta+1)\left(\varepsilon-2 \varepsilon_{1}\right) Q^{3}}{(\eta+2)\left(\varepsilon+\varepsilon_{1}\right)-(\eta-1)\left(\varepsilon-2 \varepsilon_{1}\right) Q^{3}}\left(\frac{R}{R_{1}}\right)^{3}\right] \frac{\mu \cos \Theta}{R^{2}} \\
+\psi^{\mathrm{res}}(R, \Theta, \Phi)
\end{gathered}
$$

where $\quad Q=\frac{R_{1}}{R_{2}} ; \eta=\frac{\varepsilon_{\mathrm{i}}}{\varepsilon_{1}}$

Previous investigations on solvolysis reactions ${ }^{(2-9)}$ have shown the reliability of the assumption that the potentials $\psi^{\text {res }}(R, \Theta, \Phi)$ are equal in the series of investigated esters with polar substituents. The refined model of the activated complex yields an equation of the type of Eq. (9) where $f \varepsilon, R_{1}$ ) is replaced by

$$
\begin{aligned}
& f\left(\varepsilon_{1}, \varepsilon, R_{1}, R_{2}\right) \\
& \quad=\left[1-\frac{2(1-\eta)\left(\varepsilon+\varepsilon_{1}\right)-(2 \eta+1)\left(\varepsilon-2 \varepsilon_{1}\right) Q^{3}}{(\eta+2)\left(\varepsilon+\varepsilon_{1}\right)-(\eta-1)\left(\varepsilon-2 \varepsilon_{1}\right) Q^{3}}\left(\frac{R}{R_{1}}\right)^{3}\right]
\end{aligned}
$$

The structure of the activated complexes of the investigated series shows that the ratios $Q$ and $R / R_{1}$ of Eq. (14) may be assumed to be constant. The permittivities of the bulk solution $(\varepsilon)$ and of the molecule $\left(\varepsilon_{\mathrm{j}}\right)$ also do not change. Hence the observation of different slopes of $\left(\ln k-\ln k_{0}\right) v s . \Delta\left(\mu \cos \Theta / R^{2}\right)$ may be discussed on the basis of local permittivites $\varepsilon_{1}$ in the solvation shells of the activated complexes.

\section{Experimental}

The rate constants of the alkaline hydrolysis of 2-methylpropionic acid ethyl ester, $\alpha$-hydroxy, $\alpha$-bromo, $\alpha$-cyano, and $\alpha$-nitro 2 methylpropionic acid ester have been measured in water at $5^{\circ} \mathrm{C}$ to $45^{\circ} \mathrm{C}$.

\subsection{Materials}

The 2-methylpropionic acid, $\alpha$-hydroxy and $\alpha$-bromo 2-methylpropionic acid ethyl esters are commercially available and were purfied by fractional distillation. The $\alpha$-cyano 2 -methylpropionic acid ethyl ester was prepared from cyano acetic acid ethyl ester by reaction of 2 equivalents of methyl iodide and sodium metal in absolute ethanol ${ }^{(12)}$ (Method A). After the separation of cyano monomethyl acetic acid ethyl ester by washing with $10 \%$ aqueous sodium hydroxide the ester was extracted with ether and purified by fractional distillation. 
Table I. Analytical and Physical Data of Polar Subsituted 2-Methylpropionic Acid Ethylesters

\begin{tabular}{|c|c|c|c|c|c|}
\hline Substance & $\begin{array}{l}\text { Origin } \\
\text { Prep. }\end{array}$ & $\begin{array}{c}\text { Purity } \\
\text { Yield \% }\end{array}$ & $\begin{array}{c}B_{\mathrm{p}}^{a} \\
\text { Pressure }^{b}\end{array}$ & $\alpha^{c}$ & Ref. \\
\hline $\mathrm{HC}\left(\mathrm{CH}_{3}\right)_{2} \mathrm{CO}_{2} \mathrm{C}_{2} \mathrm{H}_{5}$ & Merck & $\mathrm{z.S} \mathrm{S}^{d}$ & $110.5 / 760$ & 1.3871 & $1.3873^{e}$ \\
\hline $\mathrm{BrC}\left(\mathrm{CH}_{3}\right)_{2} \mathrm{CO}_{2} \mathrm{C}_{2} \mathrm{H}_{5}$ & Merck & z.S. ${ }^{d}$ & $63 / 15$ & 1.4450 & $1.4448 f$ \\
\hline $\mathrm{HOC}\left(\mathrm{CH}_{3}\right)_{2} \mathrm{CO}_{2} \mathrm{C}_{2} \mathrm{H}_{5}$ & Merck & z.S..$^{d}$ & $45 / 14$ & 1.4075 & $1.4080^{g}$ \\
\hline $\mathrm{NCC}\left(\mathrm{CH}_{3}\right)_{2} \mathrm{CO}_{2} \mathrm{C}_{2} \mathrm{H}_{5}$ & A & $63 \%$ & $75 / 15$ & & \\
\hline $\mathrm{O}_{2} \mathrm{NC}\left(\mathrm{CH}_{3}\right)_{2} \mathrm{CO}_{2} \mathrm{C}_{2} \mathrm{H}_{5}$ & B & $60 \%$ & $87 / 16$ & & \\
\hline
\end{tabular}

${ }^{a}$ Units: ${ }^{\circ} \mathrm{C} .{ }^{b}$ Units: Torr. ${ }^{c}$ Refractive Index. ${ }^{d}$ For Synthesis. ${ }^{e}$ Ref. $15 .{ }^{f}$ Ref. 16. ${ }^{g}$ Ref. 17.

The $\alpha$-nitro 2-methylpropionic acid ethyl ester was prepared by the reaction of $\alpha$-bromo 2-methylpropionic acid ethyl ester with $\mathrm{NaNO}_{2}$ in absolute dimethoxysulfoxide ${ }^{(13)}$ (Method B). After removal of the solvent the ester was purified by fractional distillation. Origin, preparation and characteristic physical data of all investigated esters are given in Table I. The esters were analyzed by ${ }^{1} \mathrm{H}-\mathrm{NMR}$ spectra and elementary analysis. Sodium hydroxide was used from stock solutions (Merck, p.A., $0.1 N$ ). Water was triply distilled in a quartz apparatus under nitrogen atmosphere. Ethanol was purified according to standard procedures. ${ }^{(14)}$

\subsection{Kinetic Measurements}

The kinetic experiments were performed under nitrogen atmosphere with the help of a conductometric device developped in our laboratory consisting of a thermostatted conductance cell and an appropriate AC-bridge. The conductance cell made from polypropylene with stainless steel electrodes (cell constant $1.658 \mathrm{~cm}^{-1}$ ), is immersed in a high precision thermostat with long time deviations of less than $2 \times 10^{-3}$ $\mathrm{K}$ and a temperature accuracy of $0.01 \mathrm{~K}$. Mixing of the solutions was performed with the help of a motor driven vibration mixer yielding mixing times of less than $0.25 \mathrm{~s}$. After reaching the temperature equilibrium of the conductance cell filled with aqueous hydroxyde solution, the esters which are insoluble in water and therefore were prepared as concentrated solutions in ethanol, were injected into the measuring cell with the help of a spring driven syringe. The initial concentrations were calculated via the weights of the solvent and the stock solutions with the help of known densities. The ratio of the volumes of ethanol to water 
was less than 0.005 ; therefore the addition of the ester solution doesn't produce any detectable solvent effect.

The time-dependent resistances $R(t)$ related to the progress of the solvolysis reaction, were recorded using a linear conductance AC-bridge with an operational amplifier as detector device, ${ }^{(18)}$ see Fig. 4.

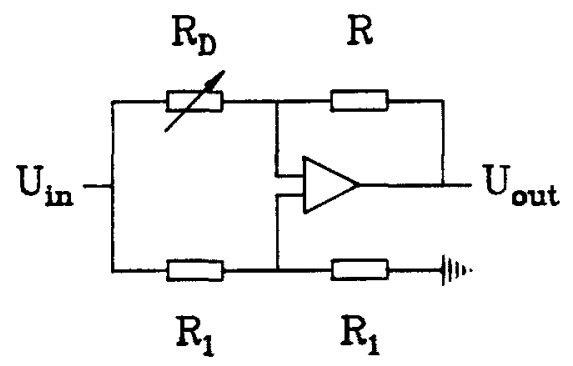

Fig. 4. Scheme of the linear conductance bridge with operational amplifier.

At equal resistances $R_{1}$ of the reference branch the output voltage of the operational amplifier is given by

$$
U_{\text {out }}=-\frac{U_{\text {in }}}{2}\left[1-R(\mathrm{t}) / R_{\mathrm{D}}\right]
$$

$R_{\mathrm{D}}$ is the decade resistance held constant during the measurement; $R(\mathrm{t})$ is the time-dependent resistance of the reacting solution. The imaginary part of the output signal, due to capacitances of the conductance cell, is automatically cancelled by a phase shift device with capacitor diodes in the branch of the decade resistance. The time-independent resistances before the beginning and at the end of the reaction are $R_{0}$ and $R_{\infty}$, respectively; $R_{\mathrm{a}}$ is the resistance corresponding to complete removal of the base. It is determined together with the remaining base concentration $c_{\mathrm{OH}^{-}}^{0}-c_{\mathrm{Ester}}^{0}$ by a conductometric titration.

After correction for the base line (conductance of the sodium hydroxide solution without ester) the rate constants $k$ are obtained by data analysis of the second order rate equation

$$
R(\mathrm{t})=\frac{R_{\mathrm{a}}\left(R_{\infty}-R_{0}\right)-R_{\infty}\left(R_{\mathrm{a}}-R_{0}\right) \exp \left[k\left(c_{\mathrm{OH}^{-}}^{0}-c_{\mathrm{Ester}}^{0}\right) t\right]}{\left(R_{\infty}-R_{0}\right)-\left(R_{\mathrm{a}}-R_{0}\right) \exp \left[k\left(c_{\mathrm{OH}}^{0}-c_{\mathrm{Ester}}^{0}\right) t\right]}
$$

with the help of a general program for the optimization of linear and nonlinear functions. The resistances $R_{0}$ and $R_{\infty}$ and the rate constant $k$ of the reaction are the fitting parameters. $R_{\mathrm{a}}$ is held constant in the statistical data analysis. 
Table II. Rate Constants $k$ of the Alkaline Hydrolysis of the Ethyl Esters of Polar Substituted 2-Methylpropionic Acids

\begin{tabular}{|c|c|c|c|c|c|c|}
\hline & $20.0^{\circ} \mathrm{C}$ & $25.0^{\circ} \mathrm{C}$ & $\begin{array}{c}k^{a} \\
30.0^{\circ} \mathrm{C}\end{array}$ & $35.0^{\circ} \mathrm{C}$ & $40.0^{\circ} \mathrm{C}$ & $45.0^{\circ} \mathrm{C}$ \\
\hline $\mathrm{HC}\left(\mathrm{CH}_{3}\right)_{2} \mathrm{CO}_{2} \mathrm{C}_{2} \mathrm{H}_{5}$ & & $\begin{array}{c}0.058 \\
\pm 0.002 \\
0.030^{b}\end{array}$ & $\begin{array}{r}0.082 \\
\pm 0.003\end{array}$ & $\begin{array}{r}0.090 \\
\pm 0.002\end{array}$ & $\begin{array}{r}0.110 \\
\pm 0.002\end{array}$ & $\begin{array}{r}0.152 \\
\pm 0.003\end{array}$ \\
\hline $\mathrm{HOC}\left(\mathrm{CH}_{3}\right)_{2} \mathrm{CO}_{2} \mathrm{C}_{2} \mathrm{H}_{5}$ & $\begin{array}{r}0.102 \\
\pm 0.002\end{array}$ & $\begin{array}{r}0.155 \\
\pm 0.006 \\
0.155^{c} \\
0.148^{d}\end{array}$ & $\begin{array}{r}0.212 \\
\pm 0.004\end{array}$ & $\begin{array}{r}0.287 \\
\pm 0.01\end{array}$ & $\begin{array}{r}0.391 \\
\pm 0.009\end{array}$ & $\begin{array}{l}0.514 \\
\pm 0.03\end{array}$ \\
\hline \multirow[t]{2}{*}{$\mathrm{O}_{2} \mathrm{NC}\left(\mathrm{CH}_{3}\right)_{2} \mathrm{CO}_{2} \mathrm{C}_{2} \mathrm{H}_{5}$} & $\begin{array}{r}0.323 \\
\pm 0.011\end{array}$ & $\begin{array}{r}0.485 \\
\pm 0.004\end{array}$ & $\begin{array}{r}0.746 \\
\pm 0.005\end{array}$ & $\begin{array}{r}1.056 \\
\pm 0.012\end{array}$ & $\begin{array}{r}1.52 \\
\pm 0.03\end{array}$ & $\begin{array}{r}2.13 \\
\pm 0.03\end{array}$ \\
\hline & $5.0^{\circ} \mathrm{C}$ & $10.0^{\circ} \mathrm{C}$ & $15.0^{\circ} \mathrm{C}$ & $20.0^{\circ} \mathrm{C}$ & $25.0^{\circ} \mathrm{C}$ & $30.0^{\circ} \mathrm{C}$ \\
\hline $\mathrm{BrC}\left(\mathrm{CH}_{3}\right)_{2} \mathrm{CO}_{2} \mathrm{C}_{2} \mathrm{H}_{5}$ & $\begin{array}{r}0.156 \\
\pm 0.003\end{array}$ & $\begin{array}{c}0.202 \\
\pm 0.01\end{array}$ & $\begin{array}{r}0.253 \\
\pm 0.007\end{array}$ & $\begin{array}{r}0.290 \\
\pm 0.005\end{array}$ & $\begin{array}{r}0.350 \\
\pm 0.003\end{array}$ & $\begin{array}{r}0.490 \\
\pm 0.006\end{array}$ \\
\hline $\mathrm{NCC}\left(\mathrm{CH}_{3}\right)_{2} \mathrm{CO}_{2} \mathrm{C}_{2} \mathrm{H}_{5}$ & $\begin{array}{r}3.35 \\
\pm 0.04\end{array}$ & $\begin{array}{r}4.33 \\
\pm 0.06\end{array}$ & $\begin{array}{r}5.3 \\
\pm 0.1\end{array}$ & $\begin{array}{r}6.5 \\
\pm 0.1\end{array}$ & $\begin{array}{l}7.7 \\
\pm 0.06\end{array}$ & \\
\hline
\end{tabular}

${ }^{a}$ Units: 1-mol ${ }^{-1}-\mathrm{s}^{-1} .{ }^{b}$ Ref. 19. ${ }^{c}$ Ref. 20. ${ }^{d}$ Ref. 21.

Table III. Activation Quantities of the Alkaline Hydrolysis of the Ethyl Esters of Polar Substituted 2-Methylpropionic Acids

\begin{tabular}{lccr}
\hline Substance & $\Delta G^{\ddagger a}$ & $\Delta H^{\ddagger a}$ & $-\Delta S^{\ddagger b}$ \\
\hline $\mathrm{HC}\left(\mathrm{CH}_{3}\right)_{2} \mathrm{CO}_{2} \mathrm{C}_{2} \mathrm{H}_{5}$ & 80.1 & 32.5 & 159.6 \\
$\mathrm{HOC}\left(\mathrm{CH}_{3}\right)_{2} \mathrm{CO}_{2} \mathrm{C}_{2} \mathrm{H}_{5}$ & 77.6 & 46.9 & 102.9 \\
$\mathrm{O}_{2} \mathrm{NC}\left(\mathrm{CH}_{3}\right)_{2} \mathrm{CO}_{2} \mathrm{C}_{2} \mathrm{H}_{5}$ & 74.8 & 56.1 & 62.8 \\
$\mathrm{BrC}\left(\mathrm{CH}_{3}\right)_{2} \mathrm{CO}_{2} \mathrm{C}_{2} \mathrm{H}_{5}$ & 75.6 & 27.6 & 160.2 \\
$\mathrm{NCC}\left(\mathrm{CH}_{3}\right)_{2} \mathrm{CO}_{2} \mathrm{C}_{2} \mathrm{H}_{5}$ & 67.1 & 33.1 & 113.8 \\
\hline
\end{tabular}

${ }^{a}$ Units: $\mathrm{kJ}-\mathrm{mol}^{-1} \cdot{ }^{b}$ Units: J-K ${ }^{-1}-\mathrm{mol}^{-1}$

\section{Results}

The experimental rate constants of the alkaline hydrolysis of the ethyl esters of polar substituted 2-methylpropionic acids are compiled in Table II. They are mean values from 3-4 measurements. Table II also shows the rate constants at $25^{\circ} \mathrm{C}$ which are known from the literature. 
Table IV. Substituent Parameters of Polar Substituted Esters

\begin{tabular}{|c|c|c|c|c|c|c|}
\hline $\mathrm{X}$ & Bond & $R^{a}$ & $\cos \theta^{b}$ & $\mu_{\mathrm{C}-\mathrm{X}}^{b}$ & $\Delta\left[\mu\left(\cos \theta / R^{2}\right)\right]^{c}$ & $\log k / k_{0}$ \\
\hline \multicolumn{7}{|c|}{ 2-Methylpropionic Acid Esters ${ }^{e} \quad \mathrm{XC}\left(\mathrm{CH}_{3}\right)_{2} \mathrm{CO}_{2} \mathrm{C}_{2} \mathrm{H}_{5} \quad \varepsilon=78.5$} \\
\hline H & C-H & 0.263 & 0.469 & -0.4 & 0.0 & 0.0 \\
\hline HO & $\mathrm{HO}-\mathrm{C}$ & 0.315 & 0.674 & 0.3 & 0.047 & 0.43 \\
\hline $\mathrm{Br}$ & $\mathrm{Br}-\mathrm{C}$ & 0.285 & 0.580 & 1.39 & 0.126 & 0.78 \\
\hline $\mathrm{NC}$ & $\mathrm{NC}-\mathrm{C}$ & 0.316 & 0.675 & 3.6 & 0.271 & 2.12 \\
\hline $\mathrm{O}_{2} \mathrm{~N}$ & $\mathrm{O}_{2} \mathrm{~N}-\mathrm{C}$ & 0.317 & 0.677 & 3.0 & 0.231 & 0.92 \\
\hline \multicolumn{7}{|c|}{ trans-Cyclohexanecarbonic Acid Ethyl Esters $f \mathrm{XC}_{6} \mathrm{H}_{10} \mathrm{CO}_{2} \mathrm{C}_{2} \mathrm{H}_{5} \quad \varepsilon=56.5$} \\
\hline $\mathrm{H}$ & $\mathrm{C}-\mathrm{H}$ & 0.470 & 0.676 & -0.4 & 0.0 & 0.0 \\
\hline HO & $\mathrm{HO}-\mathrm{C}$ & 0.530 & 0.750 & 0.3 & 0.020 & 0.37 \\
\hline $\mathrm{NC}$ & $\mathrm{NC}-\mathrm{C}$ & 0.535 & 0.750 & 3.6 & 0.107 & 0.69 \\
\hline \multicolumn{7}{|c|}{ Bicyclo-Octanecarbonic Acid Ethyl Esters ${ }^{g} \quad \mathrm{XC}_{8} \mathrm{H}_{14} \mathrm{CO}_{2} \mathrm{C}_{2} \mathrm{H}_{5} \quad \varepsilon=29.6$} \\
\hline $\mathrm{H}$ & $\mathrm{C}-\mathrm{H}$ & 0.530 & 0.977 & -0.4 & 0.0 & 0.0 \\
\hline $\mathrm{HO}$ & $\mathrm{HO}-\mathrm{C}$ & 0.616 & 0.976 & 0.3 & 0.022 & 0.67 \\
\hline $\mathrm{Br}$ & $\mathrm{Br}-\mathrm{C}$ & 0.541 & 0.972 & 1.39 & 0.060 & 1.02 \\
\hline $\mathrm{NC}$ & NC-C & 0.619 & 0.976 & 3.6 & 0.106 & 1.29 \\
\hline \multicolumn{7}{|c|}{ Acrylic Acid Ethyl Esters ${ }^{h} \quad \mathrm{XHC}=\mathrm{CHCO}_{2} \mathrm{C}_{2} \mathrm{H}_{5}{ }^{i} \quad \varepsilon=19.1$} \\
\hline$c i s \mathrm{H}$ & $\mathrm{C}-\mathrm{H}$ & 0.310 & 0.091 & -0.4 & 0.0 & 0.0 \\
\hline transH & $\mathrm{H}-\mathrm{C}$ & 0.367 & 0.867 & -0.4 & 0.0 & 0.0 \\
\hline $\operatorname{cis} \mathrm{Br}$ & $\mathrm{Br}-\mathrm{C}$ & 0.321 & 0.270 & 1.39 & 0.04 & 0.75 \\
\hline trans $\mathrm{Br}$ & $\mathrm{Br}-\mathrm{C}$ & 0.393 & 0.891 & 1.39 & 0.106 & 1.71 \\
\hline
\end{tabular}

${ }^{a}$ Units: nm. ${ }^{b}$ Units: D. ${ }^{c}$ Units: D-m ${ }^{-2}-10^{20}=3.3357 \mathrm{~V} .{ }^{d}$ Effective moment of the

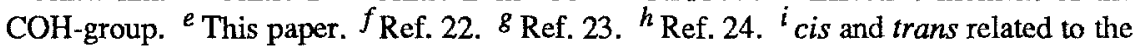
carboxyl group $\mathrm{CO}_{2} \mathrm{C}_{2} \mathrm{H}_{5}$

The activation quantities $\Delta G^{\ddagger}, \Delta H^{\ddagger}$, and $\Delta S^{\ddagger}$, derived from the temperature dependent rate constants, are given in Table III.

\section{Discussion}

Table IV shows the substituent parameters $\Delta\left(\mu \cos \Theta / R^{2}\right)$ and the differences $\left(\log k-\log k_{\mathrm{o}}\right)$ for the esters of 2-methylpropionic acids.

Figure 5 shows the dependence of the shift of $\log \left[k / k_{0}\right]$ on the substituent parameter $\Delta\left(\mu \cos \Theta / R^{2}\right)$ according to $\mathrm{Eq}$. (9) for polar substituted 2-methylpropionic acid ethyl esters [Line (2)]. Figure 5 also contains the straight line for acetic acid ethyl esters from Fig. 2 [Line (1)]. With the exception of the nitro compound where the deviation possibly is due to steric effects, the shift of the rate constants $\left(\log \left[k / k_{0}\right]\right)$ of the polar substituted 2-methylpropionic acid ethyl esters is linearly related to the substituent parameter $\Delta\left(\mu \cos \Theta / R^{2}\right)$ but with smaller slope than that of the respectively substituted acetic acid ethyl esters. 


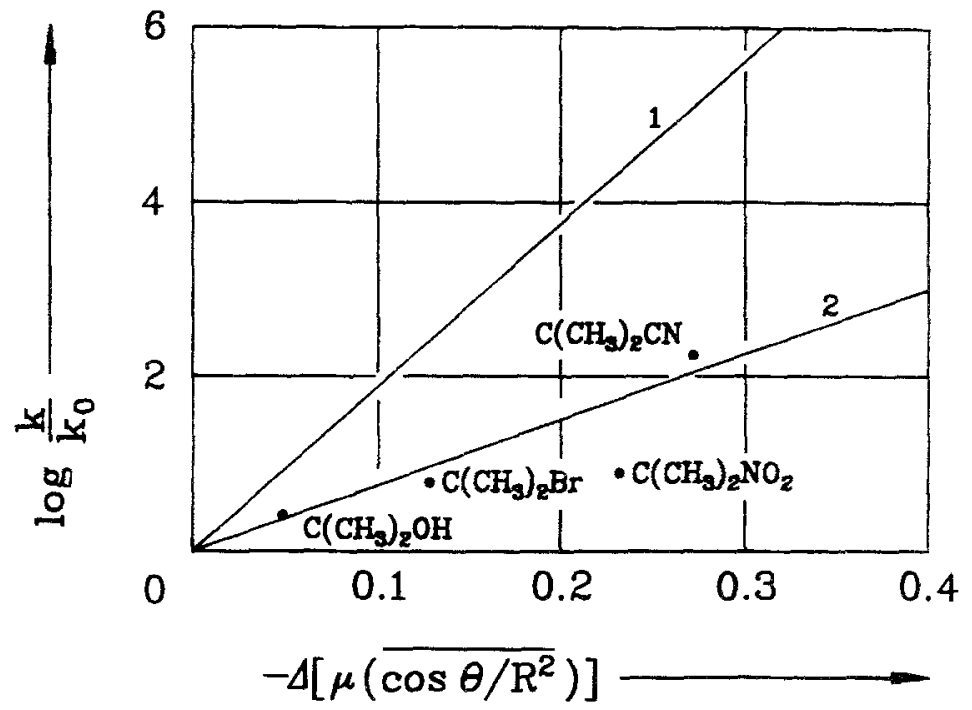

Fig. 5. Polar substituent effect, $\log \left(k / k_{\mathrm{o}}\right) v s . f\left(\Delta\left[\mu\left(\cos \theta / R^{2}\right]\right)\right.$, on the alkaline hydrolysis of substituted 2-methylpropionic acid ethyl esters (2) and acetic acid esters (1) in water at $25^{\circ} \mathrm{C}$.

The smaller influence of polar substituents on the hydrolysis reaction of methyl substituted acid esters compared to acetic acid esters is comprehensible considering the different solvation of the two compound classes in water.

Organic molecules with alkyl substituents are solvated via hydrophobic solvation in holes of the water network. The structure of the bulk water remains unchanged (or may be even reinforced). The permittivity $\varepsilon_{1}$ of the solvation shell approximately equals the permittivity $\varepsilon$ of the bulk water.

Table V. Dielectric Parameters of the Esters of Acetic and 2-Methylpropionic Acids

\begin{tabular}{lccccc}
\hline Acids & $\varepsilon_{\mathrm{i}}$ & $\varepsilon_{1}$ & $\varepsilon$ & $R_{1}{ }^{a}$ & $R_{2}{ }^{a}$ \\
\hline $\begin{array}{l}\text { Acetic acids } \\
\text { 2-Methyl- } \\
\text { propionic Acids }\end{array}$ & 2 & 20 & 78.5 & 0.32 & 0.7 \\
\hline
\end{tabular}

${ }^{a}$ Units: nm.

In contrast, small organic heteronuclear molecules, such as formic 
acid derivatives are hydrophilically solvated via hydrogen-bonds and dipole-dipole interactions yielding a strongly structured solvation shell. In the dielectric model of the activated complex the permittivity $\varepsilon_{1}$ of this solvation shell is lower than $\varepsilon$ of the bulk water. There is a gradual shift between these two types of solvation with acetic acid derivatives on the 'borderline'.

With the values for $\varepsilon_{\mathrm{i}}, \varepsilon, R_{1}$, and $R_{2}$, given in Table $\mathrm{V}$, the comparison of the two slopes, Eq. (14), yields $\varepsilon_{1}=20$ for acetic acid derivatives and $\varepsilon_{1}=80$ for the 2-methylpropionic acid esters. $\varepsilon_{\mathrm{i}}$ is assumed in both cases as the square of the refractive index of a polarizable molecule. The distances $R_{1}$ and $R_{2}$ for both types of esters are calculated from the slope of the experimental function for $\alpha$-methylpropionic acid esters under the assumption that $\varepsilon_{1}=\varepsilon$. They are consistent with the structural requirements of the activated complex, i.e., $R_{1}>R$ and the difference $\left(R_{2}-R_{1}\right)$ is larger than the diameter of one water molecule in order to allow the formation of a primary solvation shell.

The model for the hydrophobic solvation of the activated complex, used for the derivatives of 2-methylpropionic acid ethyl esters, reveals a consistent pattern when applied to esters of other hydrophobically solvated carboxylic acids. Table IV shows also some kinetic data and substituent parameters of 4-substituted trans-cyclohexane carbonic acid ethyl esters ${ }^{(22)}$ in $50 \mathrm{wt} \%$ methanol-water mixtures $(\varepsilon=56.5)$, 4substituted bicyclooctane carbonic acid ethyl esters ${ }^{(23)}$ in $87.3 \mathrm{wt} \%$ ethanol-water mixtures $(\varepsilon=29.6)$, and $\beta$ substituted acrylic acid ethyl esters $^{(24)}$ in $70.0 \mathrm{wt} \%$ ethanol-water mixtures $(\varepsilon=19.1)$.

It may be assumed that these hydrophobic esters show no specific solvation by water molecules in the water-organic solvent mixture. The permittivity $\varepsilon_{1}$ of the solvation shell of these esters then equals the permittivity $\varepsilon$, and the values of $\log \left[k / k_{\mathrm{o}}\right]$ depend on the permittivity $\varepsilon$ of the bulk solvent in the same manner as it is found for the 2methylpropionic acid esters. An inspection of the data of Table IV confirms this assumption; actually a more detailed analysis of the data with respect to the parameters $R_{1}$ and $R_{2}$, however, is not meaningful because of the small number of available rate constants for these compounds.

\section{Acknowledgment}

We are grateful to the Deutsche Forschungsgemeinschaft for financial support. We thank Mr. A. Engelhardt (Dipl.Ing.grad.) for the accomplishment of measurements and for help in the construction of the kinetic device. 


\section{References}

1. J. Barthel, H. J. Gores, G. Schmeer, and R. Wachter, in Topics in Current Chemistry, Vol. 111, F. L. Boschke, ed., (Springer, Heidelberg, 1983) p. 33.

2. J. Barthel and G. Schmeer, in Reaction Transition States, J. E. Dubois, ed., (Gordon and Breach, New York, 1972) p. 211.

3. J. Barthel and G. Schmeer, in A Centenary Report, T. A. Bak, ed., (University of Copenhagen, Copenhagen, 1984) p. 87.

4. J. Barthel, G. Bäder, and G. Schmeer, Z. Phys. Chem. N. F. 62, 63 (1968).

5. J. Barthel and G. Schmeer, Z. Phys. Chem. N. F. 71, 102 (1970).

6. J. Barthel, G. Bäder, and M. Raach-Lenz, Z. Phys. Chem. N. F. 103, 135 (1976).

7. J. Barthel and M. Raach-Lenz, Z. Phys. Chem. N. F. 103, 149 (1976).

8. G. Schmeer and J. Barthel, Z. Phys. Chem. N. F. 140, 17 (1984).

9. G. Schmeer, S. Riembauer, and J. Barthel, Z. Phys. Chem. N. F. 165, 45 (1989).

10. Tables of Interatomic Distances and Configuration in Molecules and Ions, Spec.

Publ. Nos. 11, 18, A. D. Mitchell, L. C. Cross, and L. E. Sutton, eds., (Chemical Saciety, London, 1965, 1985).

11. O. Exner, Dipole Moments in Organic Chemistry (G. Thieme Publishers, Stuttgart, 1975).

12. S. S. Biechler and W. Taft, Jr., J. Am. Chem. Soc. 79, 4927 (1957).

13. N. Kornblum, R. K. Blackwood, and J. W. Powers, J. Am. Chem. Soc. 79, 2507 (1957).

14. P. Walden, H. Ulich, and F. Laun, Z. Phys. Chem. 114, 275 (1925).

15. W. G. Braun, D. F. Spooner, and M. R. Fenske, Anal. Chem. 22, 1074 (1950).

16. Y. R. Naves, Helv. Chim. Acta 31, 151 (1948).

17. H. E. Hofmann and E. W. Reid, Ind. Eng. Chem. 21, 955 (1929).

18. U. Tietze and C. Schenk, Halbleiter-Schaltungstechnik (Springer, Berlin, 1971).

19. E. A. Halonen, Acta Chem. Scand. 10, 485 (1956).

20. M. J. Rand and L. P. Hammett, J. Am. Chem. Soc. 72, 287 (1950).

21. J. Saldick and L. P. Hammett, J. Am. Chem. Soc. 72, 283 (1950).

22. S. Siegel and J. M. Komarmy, J. Am. Chem. Soc. 82, 2547 (1960).

23. J. D. Roberts and W. T. Moreland Jr, J. Am. Chem. Soc. 75, 2167 (1953).

24. K. Bowden, Can. J. Chem. 44, 661 (1966). 